\title{
Assessments of Gaseous and Particulate Matter Emissions from Biomass Combustion and their Effect on Human Health
}

\author{
Marzouk Lajili* \\ Department of Physics IPEIM, Tunisia
}

*Corresponding author: Marzouk Lajili, Department of Physics IPEIM, UR EMIR (Etude des Milieux Ionisés et Réactifs), 15 Avenue Ibn Eljazzar IPEIM, 5019 Monastir Tunisie

\section{ARTICLE INFO}

Received: 㓞 April 12, 2019

Published: 幽 April 22, 2019

Citation: Marzouk Lajili. Assessments of Gaseous and Particulate Matter Emissions from Biomass Combustion and their Effect on $\mathrm{Hu}$ man Health. Biomed J Sci \& Tech Res 17(2)-2019. BJSTR. MS.ID.002979.
ABSTRACT

Aerosol particles (PM) play important roles either on the climate and environment mitigations or on human health. The object of this paper is to study the PMs Emissions during combustion of pellets prepared from lignocellulosic biomass in a small power household boiler $(8-12 \mathrm{~kW})$. Greenhouse and toxicant gaseous emissions including $\mathrm{CO}_{2}$ and steam $\left(\mathrm{H}_{2} \mathrm{O}\right)$, and $\mathrm{CO}, \mathrm{NOx}\left(\mathrm{NO}+\mathrm{NO}_{2}\right)$, Volatile organic compounds (VOC) and $\mathrm{O}_{2}$ in the flue gas were analyzed and measured. Moreover, we used the so-called Electrical Low Pressure Impactor technique (ELPI, Dekati) for aerosol particles (PM) assessments. Results show that aerosols are distributed between fine and ultrafine particles for which the median aerodynamic diameter ranges from $20 \mathrm{~nm}$ to $10 \mu \mathrm{m}$. These PM are at the origin of many harmful health diseases affecting the brain, the lungs and the cardiovascular systems.

Keywords: Pellets; Combustion; Gaseous Emissions; Aerosols; Health Diseases

\section{Introduction}

Currently, our existence on the Earth planet is being highly threatened because of many apocalypse scenarios in relation with environmental pollution phenomenon. These various pollutions are caused by both anthropogenic and industrial activities. Indeed, the gaseous and the particulate emissions which are harmful for the fauna and the flora are in continuous increase up to a critical point at which we computed more than 10000 organic PMs in an urban atmosphere [1,2]. Nevertheless, it exists always a dispatching concern over the planet warm and the aerosols which are suspensions of solid and liquid particles in air. Indeed, the most crucial factor that governs the climate change over the twenty-first century is the Equilibrium climate sensitivity (ECS) caused mainly by the greenhouse gases; $\mathrm{CO}_{2}, \mathrm{H}_{2} \mathrm{O}, \mathrm{CH}_{4}, \mathrm{~N}_{2} \mathrm{O}$ etc. It is defined based on the increase in the planet mean surface temperature resulting from doubling of $\mathrm{CO}_{2}$ concentration in the atmosphere when it is coupled to a slab ocean model [3]. It is to be mentioned that this factor (ECS) of every climate model ever developed has given always positive value. This is a strong indication of warmer equilibrium climate when the $\mathrm{CO}_{2}$ content is in a continuous increase in the atmosphere and everybody knows that it is currently the case. In addition all tested models in the project of the $4^{\text {th }}$ Assessment report of the Intergovernmental Panel on Climate Change (IPCC) show an ECS in the range of $2-4.5^{\circ} \mathrm{C}[4]$.

Researchers' interests to aerosols are relatively recent by comparison to greenhouse emissions. However, the aerosols particles can also play an important role on the global climate change [5-6]. Indeed, they can either intensify or moderate the greenhouse gases effects via the scattering or the absorption of both external solar radiation and thermal Earth's surface emitted radiation. Phenomenon of scattering and absorption of light by aerosols depend strongly on the aerosols size distribution, their chemical composition and the wave length of the incident radiation [7]. It is to be highlighted that the scattering is predominately a function of particle size, morphology and chemical composition, and it concern mainly PMs in the range of $0.1-1 \mu \mathrm{m}$. However, the absorption by aerosols is related to the whole spectrum and is due to near-graphitic carbon (known under elemental or black carbon) produced via combustion process [7]. In addition, the aerosols under the cloud condensation nuclei are able to modify substantially the radiative properties of the atmosphere. Moreover, despite the low aerosol's concentrations $10^{-10}$ to $10^{-14}$ (which is the volumetric ratio of aerosol particles to atmospheric gases) 
their effect on the atmosphere change is significant [8]. However, aerosols particles don't contribute only on violent climate change, but also affects human health seriously.

Indeed, air we continuously inhaling is enriched with particulate matter pollutants from many different sources. These PMs are of many types depending on the geographical distribution, area, anthropogenic and industrial activity, and season. Workers in industrial field are more exposed to air pollution. It is proven that aerosols produce serious effects on different parts of our body; the skin, the arteries, the lungs, the heart and the eyes as it is illustrated below (Figure 1) [9-15]. Also, the brain can be affected by aerosols depending on the particle size and charge [16]. In fact, the biological effects depend strongly on the PM characteristics. Indeed, it was shown that the size of PM is the crucial parameter which regulated its potential to make an injury, an oxidative, an inflammatory and other biological response [17-18]. The residence time which is the time for which the patient is exposed to aerosols inhalation is also an important factor. More precisely sustained long-time exposure yields to serious cardiovascular, respiratory, and skin diseases. However, short-time exposure can cause morbidity incidents in all ages by cardiovascular and respiratory diseases due to airborne dust particles [19].

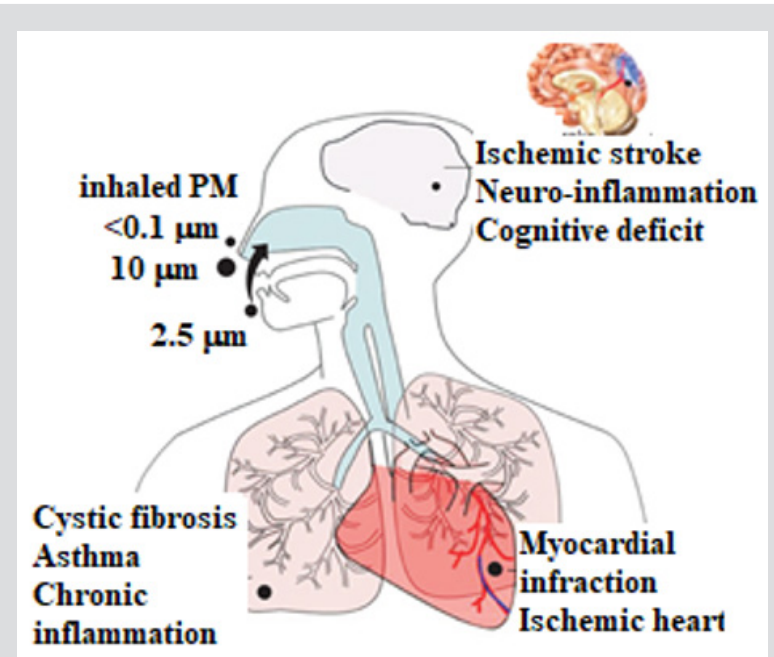

Figure 1: The effects of ultrafine and fine aerosols on human health by air inhalation.

It is worth noting that aerosol particles emitted during biomass burning are the most optically active [20] because of their size, in the submicrometer interval, their accumulation mode particles, and their high content of high-absorbing components. Moreover, the biomass burning activities are usually occurring in the underdeveloped countries located in tropical regions such as Africa, East of Asia and the south of America [21]. Indeed, in these regions of world fire is routinely cooking, heating, and also used for deforestation and seasonal burning of cereal straw and pastures. For these reasons, our attention is focused on aerosols and gaseous emissions during pellets combustion in a household boiler of a small power $(8-12 \mathrm{~kW})$. for this purpose, different samples were prepared by blending lignocellulosic biomasses; olive mill solid/ liquid wastes and pine sawdust in different mass fractions. Even though the ökofen automatic boiler was designed for being fed with woody pellets, we have conducted these combustion tests to assess gaseous emissions such as $\mathrm{CO}, \mathrm{CO}_{2}, \mathrm{C}_{\mathrm{n}} \mathrm{H}_{\mathrm{m}}$ (mainly $\mathrm{CH}_{4}$ ) and $\mathrm{NO}_{\mathrm{x}}$ using appropriate gas analyzer. For assessing the aerosol particles an Electrical Low Pressure Induced (ELPI) technique was considered.

\section{Materials and Methods}

Different residues from agrifood industry were collected for this study; grape marc (GM) obtained from a winery (Bouargoub, Tunisia), tomato waste (TW) obtained from a concentrate tomato factory (Kairouan, Tunisia), The raw olive mill solid waste (OMSW), the exhausted olive mill solid waste (EOMSW) were purchased from the oil and soap factory of Zouila situated in the region of
Mahdia (Tunisia). Also, the olive mill wastewater (OMWW) was collected from the same company. These residues impregnated or not by OMWW were blended with pine sawdust (PS) collected from carpentry of wood (Sayada, Tunisia). During each impregnation test, $20 \mathrm{~kg}$ of EOMSW or PS with $10 \%$ of moisture (wet basis, w. b.) were added to $100 \mathrm{~kg}$ of OMWW characterized by $90 \%$ of moisture (W. b.) in a barrel as it was reported in our previous work [22]. The used process to produce different pellets was meticulously described in our previous works $[22,23]$. The prepared pellets are characterized by an average length close to $3 \mathrm{~cm}$ and a mean diameter close to $0.6 \mathrm{~cm}$. Based on the raw material of departure, seven types of samples were produced, namely impregnated exhausted olive mill solid waste (IEOMSW) by OMWW, impregnated pine sawdust (IPS) by OMWW, 100\%PS, 100\% EOMSW, 100\%TW, 50\%TW-50\%PS and 50\%GM-50\%PS.

Different analytical techniques respecting European standards were conducted for achieving proximate and ultimate analysis of the prepared pellets. Moisture content was determined by following EN 14774-2 (2010), ash content was determined conformingly to EN 14775 (2010). Nitrogen determination (N) was realized according to EN 15104 (2011) using CHONS elemental analyzer. Chlorine (Cl) and Sulphur (S) contents were estimated following EN 15289 (2011). The technique of Inductively Coupled Plasma-atomic emission Spectroscopy (ICP-AES) was considered for determining the major inorganic elemental analysis according to EN 15290 (2011). The minor element analysis was carried out according to NF EN ISO 16968 (2015). The technique of adiabatic 
bomb calorimeter (IKA C200) was chosen for the high heating value (HHV) determination, and low heating value (LHV) can be easily deduced by taking into account the latent heat of water evaporation/condensation. The energetic characteristics of each sample's type can be exhibited via its LHV, its bulk density (BD) and energy density (ED) which is the product of LHV and BD.

\section{Experimental Device and Methods}

The experimental bench (Figure 2) as well as the experimental protocol was meticulously described in previous works [22-24]. This setup which was designed for laboratory purposes allows to run at different feed levels and to test different types of solid fuels prepared from biomass.

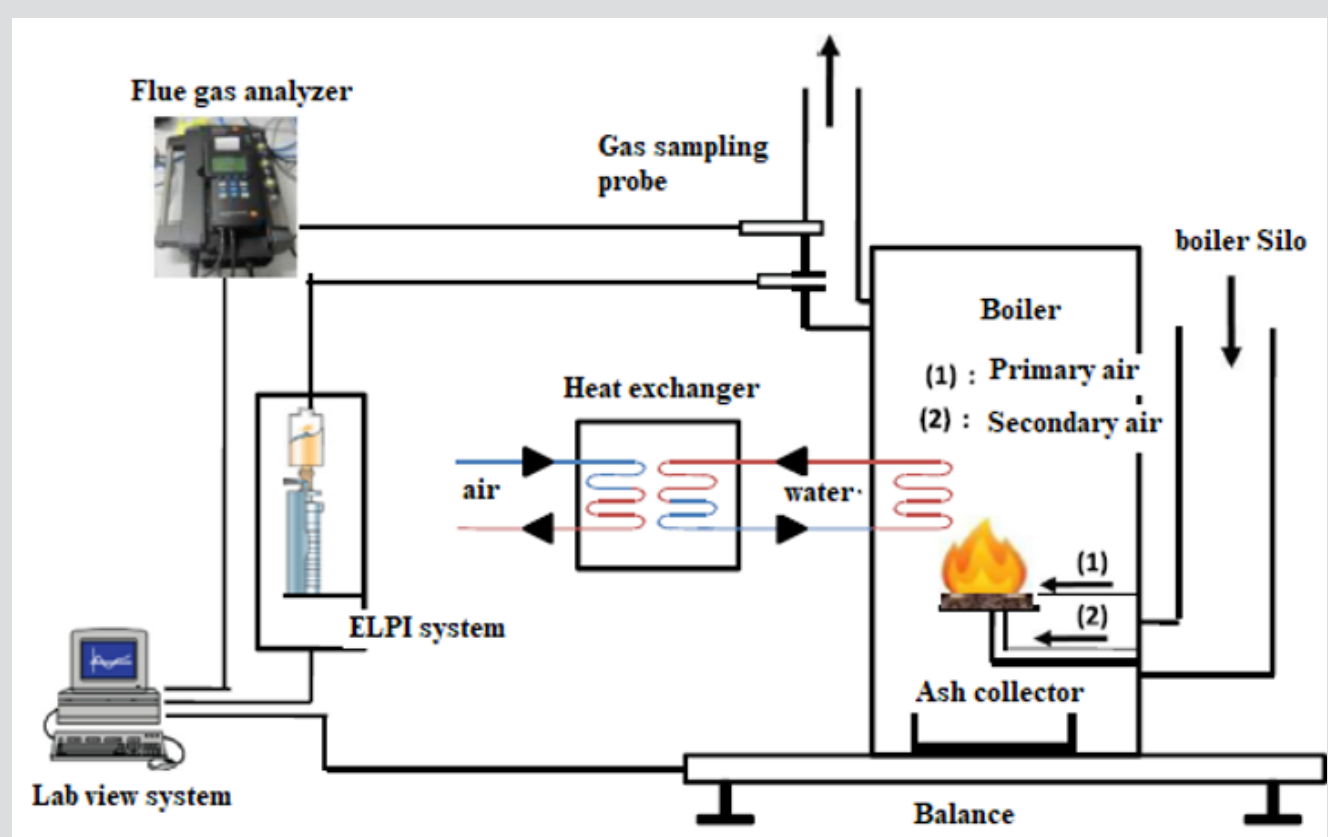

Figure 2: Combustion Device with gas analyzer and particulate matter detection.

Gaseous Emissions and Aerosols Analyses: The gas analyzer and Physico-chemical based on which it was designed were meticulously described [22-25]. Moreover, an electrical low pressure Impactor (ELPI, Dekati) was used in order to assess the number and the concentration of ultrafine and fine particles, and more precisely characterized by hydraulic diameters ranging between $29 \mathrm{~nm}$ and $10 \mu \mathrm{m}$ in our case. This technique consists at ionizing the particles according to their Stokes diameter when penetrating the system.
Indeed, the aerosols are charged in a positive unipolar particle charger named corona charger. Then, the aerosols penetrated the cascade Impactor in order to be segregated on the basis of their inertia and their aerodynamic diameter as it is illustrated on Figure 3. A multistage electrometer measured the current intensity of the order of femtoampere $\left(1 \mathrm{fA}=10^{-15} \mathrm{~A}\right)$ and then system can count the number and the concentration of the charged aerosol particles for each stage using mathematical algorithms.

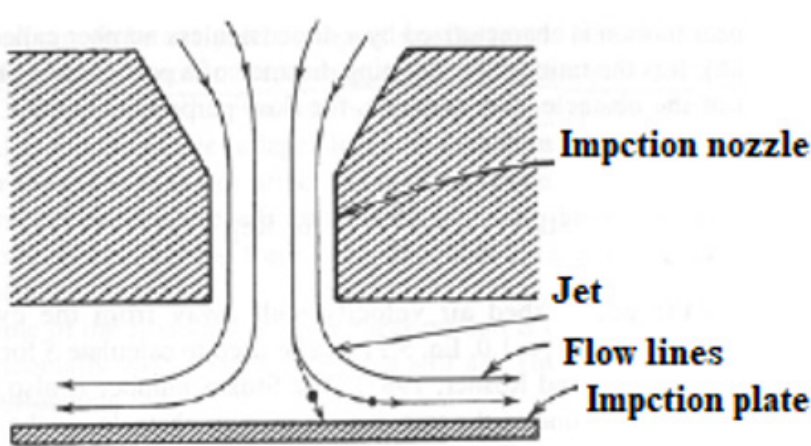

a)

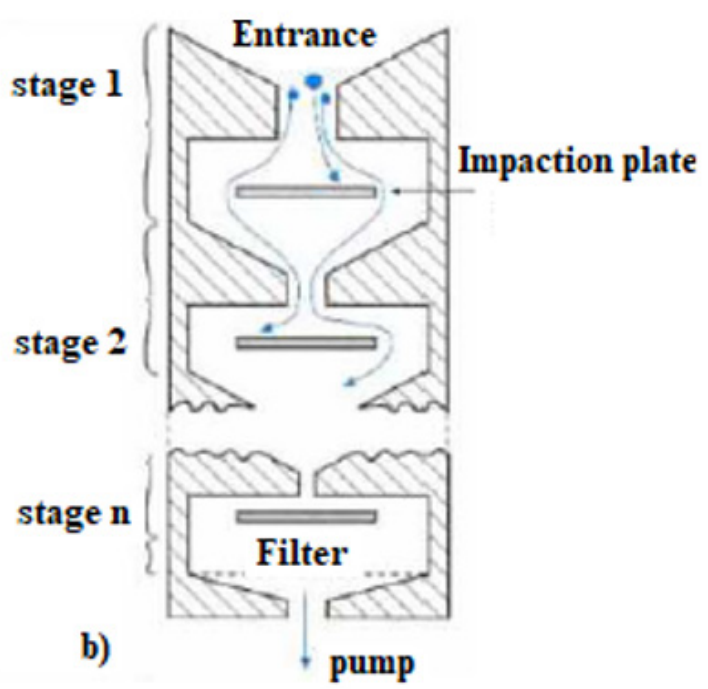

Figure 3: a. Scheme of one Impactor stage and b. scheme of cascade Impactor (13 in our case). 
Hence, the number of aerosol particles is a function of the induced measured current and of the density of the particles in the exhaust gas which has to be given by the user. It is to highlight that aerosol particles number and concentrations were calculated on the basis of using $1{\mathrm{~g} . \mathrm{cm}^{-3}}^{-3}$ of density value [26]. Moreover, total suspended aerosols (TSAs) were measured following DIN CERTCODIN EN 13229 (2008) certification rules. In order to correlate the aerosols emitted and the pellets characteristics, we realized the so-called principal component analysis (PCA) based on the XLSTAT software. This technique is widely applied in the treatment of high complexity data sets [27]. PCA technique consists at determining the eigenvalues and eigenvectors when treating the covariance matrix of original variables. All this for the goal of finding correlation between variables for which the dimensionality of the data set is significantly reduced. The eigenvalues are the measure of their associated variance.

\section{Results and Discussions}

\section{Characterization of Different Samples}

Table 1 shows the ultimate analyses and the proximate analyses of the seven different produced pellets. The moisture contents Table 1: Physico-chemical parameters of the tested pellets. are ranging between 9 and 13\% (wt. \%, db). The ash content varies between 0.6 for PS and $11 \%$ for TW (wt. \%, db). The bulk density varies between a minimum value $\left(522 \mathrm{~kg} \cdot \mathrm{m}^{-3}\right)$ of TW, and a maximum value of $690 \mathrm{~kg} \cdot \mathrm{m}^{-3}$ corresponding to IEOMSW. The LHV varies between $16.3 \mathrm{MJ} . \mathrm{kg}^{-1}$ of EOMSW and $19.8 \mathrm{MJ} . \mathrm{kg}^{-1}$ of IEOMSW. All these values are familiar for researcher in this field and in coherence with what was reported in the literature [28-33]. We noticed that the high ash values for both TW and 50GM-50PS prevent these solid fuels to be conform to the French agropellet standard ( $<7 \mathrm{wt} . \%)$. Also, the French standard couldn't be reached by TW, 50TW-50PS, EOMSW, IEOMW and IPS due to the chlorine contents ( $>0.2 \mathrm{wt} . \%)$ and sulphur ( $>0.2 \mathrm{wt}$. \%). As for the nitrogen, it is initially highly presented in the agrifood industry such as olive wastes, grape marc and tomato waste [22]. However, the prepared pellets reach the French agropellet standard (nitrogen content < 2 wt. \%), but even with this nitrogen oxide emissions should be seriously considered during combustion tests.

At the bottom of Table 1 we can read, results obtained by ICPAES, the inorganic elements contents. As it is predicted, potassium $\mathrm{K}$, chlorine $\mathrm{Cl}$ and calcium $\mathrm{Ca}$ are the main elements, whilst $\mathrm{Si}, \mathrm{Mg}$, $\mathrm{Fe}, \mathrm{P}$ and $\mathrm{Na}$ are strongly depending on the nature of the biomass.

\begin{tabular}{|c|c|c|c|c|c|c|c|c|}
\hline Parameter & Unit & IPS & IEOMSW & PS & EOMSW & TW & 50TW50PS & 50GM50PS \\
\hline Moisture & (wt. \%, ar) & 9 & 7 & 13 & 12 & 10 & 11 & 9 \\
\hline Ash & (wt. \%, db) & 4 & 7 & 0.6 & 3 & 11 & 4 & 9 \\
\hline BD & $\left(\mathrm{kg} \cdot \mathrm{m}^{-3}\right)$ & 550 & 690 & 601 & 629 & 522 & 473 & 569 \\
\hline LHV & $\left(\mathrm{MJ} \mathrm{kg}^{-1}\right)$ & 18.5 & 19.8 & 16.4 & 16.3 & 19.5 & 17.6 & 16.6 \\
\hline ED & $\left(G J \cdot m^{-3}\right)$ & 10.2 & 13.7 & 9.8 & 10.2 & 10.2 & 8.3 & 9.4 \\
\hline $\mathrm{N}$ & $(\%, \mathrm{db})$ & 1.0 & 1.8 & 0.2 & 0.8 & 1.5 & 0.8 & 1.4 \\
\hline$S$ & $(\mathrm{~g} / \mathrm{kg}, \mathrm{db})$ & 1.55 & 2.55 & 0.12 & 1.99 & 2.96 & 2.08 & 1.43 \\
\hline $\mathrm{K}$ & & 3.40 & 7.53 & 0.36 & 1.13 & 30.48 & 16.61 & 5.15 \\
\hline $\mathrm{Cl}$ & & 6.12 & 6.28 & 0.31 & 3.44 & 5.75 & 3.42 & 0.70 \\
\hline $\mathrm{Ca}$ & & 0.87 & 1.45 & 0.36 & 1.13 & 1.45 & 1.22 & 1.28 \\
\hline $\mathrm{Si}$ & & 0.16 & 0.21 & 0.01 & 0.09 & 0.19 & 0.18 & 0.21 \\
\hline $\mathrm{Na}$ & & 1.15 & 1.79 & 0.01 & 0.78 & 0.35 & 0.29 & 0.23 \\
\hline $\mathrm{P}$ & & 0.18 & 0.23 & 0.08 & 0.13 & 0.93 & 0.64 & 0.36 \\
\hline $\mathrm{Mg}$ & & 0.16 & 0.22 & 0.02 & 0.12 & 0.59 & 0.45 & 0.22 \\
\hline $\mathrm{Al}$ & & 0.09 & 0.13 & 0.01 & 0.05 & 0.12 & 0.11 & 0.20 \\
\hline $\mathrm{Fe}$ & & 0.90 & 1.00 & 0.02 & 0.04 & 0.10 & 0.10 & 0.12 \\
\hline $\mathrm{Mn}$ & & 0.02 & 0.01 & 0.05 & 0.00 & 0.09 & 0.01 & 0.01 \\
\hline $\begin{array}{l}(\mathrm{K}+\mathrm{Na}) / \\
(2 \mathrm{~S}+\mathrm{Cl})\end{array}$ & $\mathrm{Mol} / \mathrm{mol}$ & 0.51 & 0.80 & 0.59 & 0.58 & 2.29 & 1.93 & 1.30 \\
\hline
\end{tabular}

Note: $\mathrm{db}$ : dry basis; ar: as received; BD: bulk density; ED: energy density $=\mathrm{LHV} \times \mathrm{BD}$

The rest of inorganic elements appear as traces such as manganese $\mathrm{Mn}$ and aluminum Al. Due to the impregnation process, we observe that the $\mathrm{Na}$ is highly concentrated in the impregnated samples IPS and IEOMSW because the Na content is considerable in OMWW. Besides, as it was suggested by Zeng et al. [34], the sum concentrations of specified inorganic elements are crucial to explain the aerosols emission during combustion. The so-called fuel indexes defined by Zeng et al. [34] and Sommersacher et al.
[35] that we calculated in Table 1 under molar ratios $(\mathrm{K}+\mathrm{Na}) /$ $(2 \mathrm{~S}+\mathrm{Cl})$ is a crucial parameter governing the $\mathrm{PMs}\left(\mathrm{HCl}\right.$ and $\left.\mathrm{SO}_{2}\right)$ emission levels, and the slagging tendency in the bottom ash (not an objective for us in this study). We observe that $(\mathrm{K}+\mathrm{Na}) /(2 \mathrm{~S}+$ $\mathrm{Cl}$ ) is equal to 2.3 for TW pellets and is of the same order as woody and herbaceous biomass as it was reported in the literature [34]. This allows predicting that low concentrations of $\mathrm{HCl}$ and $\mathrm{SO}_{2}$ are expected in corresponding flue gas. 


\section{Combustion Parameters and Pollutant Emissions}

We collected in Table 2 the combustion parameters and the pollutants emissions (gaseous and aerosols) after carrying out combustion tests according to EN 303-5 (2012) standard. For calculations details the reader can refer to our previous work [22]. We notice that the combustion efficiency varies between a minimum value $(87.3 \%)$ for 50 TW50PS and a maximum one (91.5\%) for EOMSW. These values are in agreement with what was reported in the literature [28,31-33,36]. Also, it is found in Table 2 that the global boiler efficiency, ranging between $80.2 \%$ for GM-PS and $84.9 \%$ for IEOMSW, satisfies the minimum value of efficiency (77\%) required by EN 303-5 standard. Moreover, TW pellets present the highest aerosols emissions (2719 mg. $\mathrm{Nm}^{-3}$ ), whereas, PS pellets exhibit the lowest aerosols emissions (143 mg. $\mathrm{Nm}^{-3}$ ). This result is related to ash content in both pellets, especially as the ash content in TW (11 wt. \%) is much higher than ash content in PS (0.6 wt. \%). However, the aerosols emissions don't depend only on ash contents. Indeed, as it is seen in Table 2 the Particulate matter (PM) emissions of 50GM50PS ( $9 \mathrm{wt}$. \% ash) are lower than 50TW50PS emissions (4 wt. \%).

Table 2: Parameters of combustion and pollutant emissions.

\begin{tabular}{|c|c|c|c|c|c|c|c|c|c|c|}
\hline Sample & $q\left(\mathrm{~kg} \cdot \mathrm{h}^{-1}\right)$ & $\lambda$ & $\eta_{\text {com }}(\mathbf{\%})$ & $\eta_{\text {boiler }}(\%)$ & $\mathrm{O}_{2}$ & $\mathrm{CO}_{2}$ & Co & $N O_{x}$ & VOC & PM \\
\hline IPS & 2.3 & 2.35 & 88.2 & 81.8 & 12.1 & 8.0 & 1022 & 255 & 1207 & 659 \\
\hline PS & 2.1 & 2.61 & 91.0 & 83.4 & 15.0 & 6.0 & 346 & 116 & 914 & 143 \\
\hline IEOMSW & 2.0 & 2.07 & 91.5 & 84.9 & 10.9 & 9.0 & 631 & 223 & 491 & 1038 \\
\hline EOMSW & 2.7 & 2.40 & 88.4 & 83.7 & 12.3 & 8.0 & 993 & 384 & 777 & 558 \\
\hline TW & 2.6 & 2.10 & 88.9 & 80.6 & 12.1 & 8.0 & 495 & 428 & 566 & 2719 \\
\hline 50TW50PS & 2.4 & 2.90 & 87.3 & 81.1 & 13.7 & 7.0 & 809 & 537 & 515 & 2279 \\
\hline 50GM50PS & 2.3 & 4.7 & 90.4 & 80.2 & 16.6 & 5.0 & 631 & 456 & 602 & 966 \\
\hline
\end{tabular}

This further was explained by Zeng et al. [34] when building a correlation between the $\mathrm{K}$ content as well as the sum $(\mathrm{K}+\mathrm{Na}+\mathrm{S}$ $+\mathrm{Cl}+\mathrm{Pb}+\mathrm{Zn}$ ) expressed in $\mathrm{mg}^{\mathrm{kg}}{ }^{-1}$ with $\mathrm{PM}$ emissions expressed in $\mathrm{mg} . \mathrm{Nm}^{-3}$ when running combustion tests using pellets from Miscanthus, white straw and different mixtures with woody biomass. In addition, the flue gas analysis is a good criterion for aerosol emissions. Indeed, when working under rich combustion

\section{Distribution of PM Emissions}

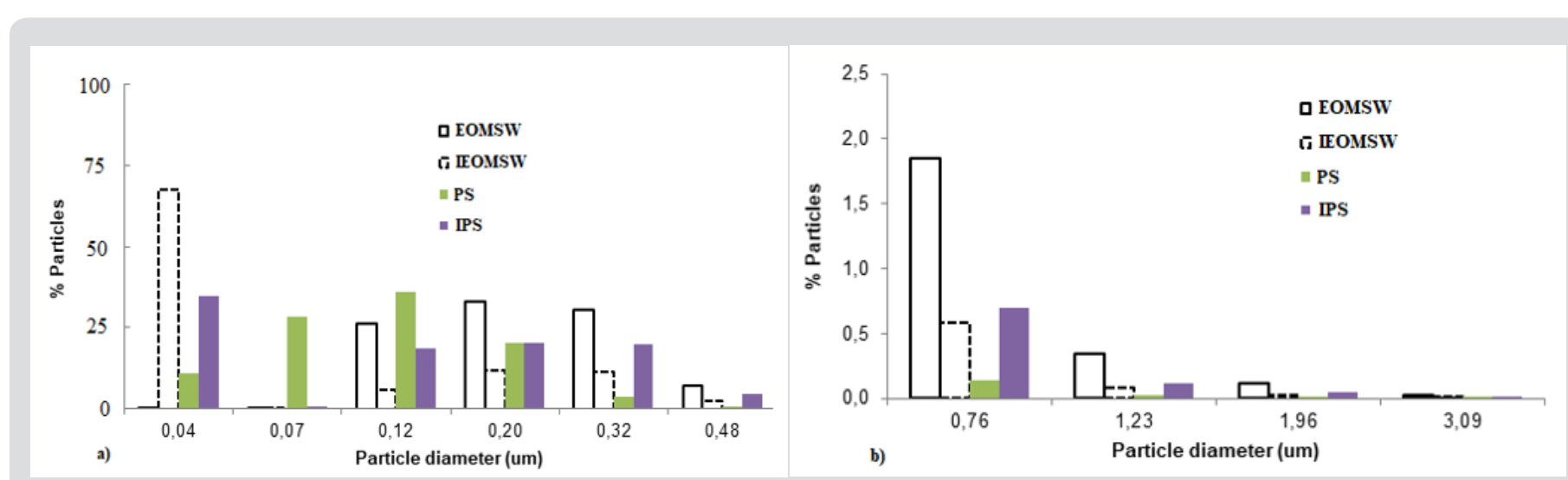

Figure 4: PM percentage distribution versus particle diameter (d) during EOMSW, IEOMSW, PS and IPS pellets combustion. a) For $\mathrm{d}<0.5 \mu \mathrm{m}$ and $\mathrm{b}$ ) for $0.7<\mathrm{d}<3.1 \mu \mathrm{m}$.

The aerosol particles were distributed according to their hydraulic diameter. They can be described by their number or their percentage as it is reported in Table 3. We notice From Table 3 and Figures $4 \& 5$ that about $99 \%$ in number of aerosols correspond to fine sub-micron particles characterized by a diameter lower than $1 \mu \mathrm{m}$. This observation is in agreement with result reported by Johansson et al. [37] when studying combustion of wood pellet briquettes. Moreover, Figure 4 shows that the blending operation using PS and the impregnation process using OMWW favorites (equivalence ratio $>1$ ), the $\mathrm{CO}$, the $\mathrm{VOC}$ and the PM emissions increase. where, $q$ is the fuel mass flow; $\lambda$ is the air factor, $\mathrm{O}_{2}$ and $\mathrm{CO}_{2}$ are the average oxygen and carbon dioxide proportions in the flue gas (vol. \%); $\eta$ is the efficiency (\%); $\mathrm{CO}, \mathrm{NO}_{\mathrm{x}^{\prime}} \mathrm{VOC}$ and $\mathrm{PM}$ are the concentrations of carbon monoxide, nitrogen oxides (NO + $\mathrm{NO}_{2}$ ), volatile organic compounds $\mathrm{C}_{\mathrm{n}} \mathrm{H}_{\mathrm{m}}$ and aerosol particles, they are all expressed in mg. $\mathrm{Nm}^{-3}$ at 10 vol. $\% \mathrm{O}_{2}$. 


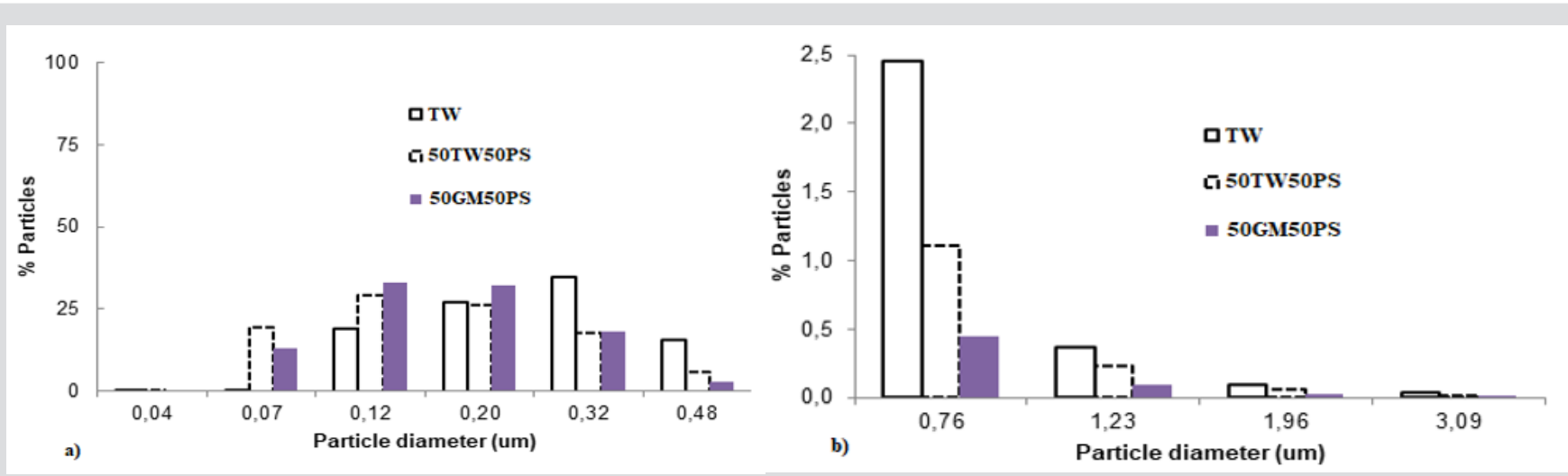

Figure 5: PM percentage distribution versus particle diameter (d) during TW, 50TW50PS and 50GM50PS pellets combustion. a) For $\mathrm{d}<0.5 \mu \mathrm{m}$ and $\mathrm{b}$ ) for $0.7<\mathrm{d}<3.1 \mu \mathrm{m}$.

These observations are may be attributed to two causes. First the PS pellets are expected to generate an important percentage of nanoparticles (39.4\%) during combustion as it is shown in Table 3. Second, the impregnation process increases the nanoparticle generation (Table 3) due to the addition of minerals present in OMWW (Table 1). These minerals may play a catalytic role during the fractioning of the soot agglomeration or condensable organic vapours. These assumptions are in agreement with the observations of Garcia-Maraver et al. [33]. Also, Sommerrsacher et al. [35] have found a correlation between the sum $(\mathrm{Na}+\mathrm{K})$ content and aerosols of diameter equal to $1 \mu \mathrm{m}$ named $\mathrm{PM}_{1}$ during the combustion tests realized on different samples. This correlation is linear with a regression factor $\mathrm{R}^{2}=0.94$. Also, in the same context Jeguirim et al. [38] have shown a linear correlation between the total PM $(\mathrm{g} / \mathrm{kg})$ and $\mathrm{K}$ and the sum $(\mathrm{K}+\mathrm{Na}+\mathrm{S}+\mathrm{Cl})$ expressed in $\mathrm{g} / \mathrm{kg}$. Furthermore, they found that the correlation with potassium is more strong with a correlation coefficient $\mathrm{R}^{2}=0.94$ than with the sum $(\mathrm{K}+\mathrm{Na}+\mathrm{S}+\mathrm{Cl})$ for which $\mathrm{R}^{2}$ is equal to 0.88 .

Table 3: Percentages of aerosol particles number for different particles diameters.

\begin{tabular}{|c|c|c|c|c|c|}
\hline Sample & $\mathbf{P M}_{\mathbf{0 . 1}}$ & $\mathbf{P M}_{\mathbf{0 . 1}-\mathbf{0 . 2 5}}$ & $\mathbf{P M}_{\mathbf{0 . 2 5 - 1 . 0}}$ & $\mathbf{P M}_{\mathbf{1 . 0 - 2 . 5}}$ & $\mathbf{P M}_{\mathbf{2 . 5 - 1 0 . 0}}$ \\
\hline IPS & 35.57 & 39.07 & 25.19 & 0.17 & 0.01 \\
\hline PS & 39.40 & 56.22 & 4.32 & 0.05 & 0.01 \\
\hline IEOMSW & 67.70 & 17.52 & 14.65 & 0.11 & 0.01 \\
\hline EOMSW & 0.52 & 59.53 & 39.46 & 0.45 & 0.03 \\
\hline TW & 0.33 & 46.11 & 53.07 & 0.28 & 0.03 \\
\hline 50TW50PS & 19.58 & 55.37 & 24.74 & 0.13 & 0.02 \\
\hline 50GM50PS & 13.21 & 65.14 & 21.51 & & 0.01 \\
\hline
\end{tabular}

In agreement with our study showing important percentages of $\mathrm{PM}_{0.1-2.5}$ for all samples, it was proven in the literature that these PM affects seriously lungs [39]. This attack is due to the contact of toxic chemical PM on the epithelium of human lung airways. These PM are generated by combustion fossil fuels, vehicle exhaust and industrial process acid, as well as volatile organic compounds such as pathogens, fungi and pollens. This problem was most accentuated for humans working in the industries of sandblasting, flint mild and the soap manufacturing. Indeed, the inhalation of asbestos for example causes directly asbestosis, and what is dangerous is that silicosis and asbestosis are incurable and even when the exposure stop the health degradation may still progress [40]. On the other hand, it is well known that the blood brain barrier protects the brain, but this latter may not operate properly and then doesn't protect the brain from PM. It was proven that various toxic effects including respiratory, cardiovascular and neurological toxicities can be caused by PM and particularly $\mathrm{PM}_{2.5}$ can easily cross the blood brain barrier.

A specific study showed that patients exposed to coal fumes are subject of an increase incidence in ischemic stroke which is the main cause of death in Shanghai for example [41]. Nevertheless, by referring to Table 3 we can say that there is no fear in our case because the percentage content of $\mathrm{PM}_{2.5}$ is not elevated (lower than $0.5 \%$ ). Moreover, it was reported in the literature that aerosols with diameters less or equal to $2.5 \mu \mathrm{m}$ was linked to many risks of cardiovascular diseases [42,43]. More deeply, these problems are due to variation of the blood composition include the irregularity of the heart rate, plasma viscosity and blood pressure regime. Also, with the increase of PM concentration the risk of myocardial infraction increases too $[42,43]$.

\section{Conclusion}

The combustion of the biomass either at raw state or densified biofuel is always at the origin of the gaseous and PM emissions. We find in the present study that the gaseous and the PM emissions are strongly depended to the nature of the different tested pellets. Also, it was demonstrated that the combustion parameters affects strongly the gaseous and the PM emissions. Moreover, the PM distribution exhibits that the highest concentrations are met with $\mathrm{PM}_{0.1-0.25}$, and $\mathrm{PM}_{0.25-1.0}$ respectively. For these particular PM sizes, 
serious harmful problems are to be taken into consideration including lungs, brain and heart.

\section{Acknowledgement}

The author would like express his deep thanks to Professors Lionel limousy and Mejdi Jeguirim from IS2M of Mulhouse for their precious technical supports.

\section{References}

1. Takahama S, Gilardoni S, Russell LM, Kilcoyne ADL (2007) Classification of multiple types of organic carbon composition in atmospheric particles by scanning transmission X-ray microscopy analysis. Atmospheric Environment 41(40): 9435-9451.

2. Hamilton JF, Webb PJ, Lewis AC, Hopkins JR, Smith S, et al. (2004) Partially oxidized organic components in urban aerosol using GCXGCTOF/MS. Atmospheric Chemistry and physics 4: 1279-1290.

3. Gent PR (2007) Climate Change Modeling Methodology: Selected Entries from the Encyclopedia of Sustainability Science and Technology, Ed P] Rasch, New York, USA.

4. Bernstein L, Bosch P, Canziani O, Chen Z, Christ R, et al. (2007) Intergovernmental Panel on Climate Change Fourth Assessment Report. Climate Change Synthesis Report 1-21.

5. Farquhar GD (1997) Carbon dioxide and vegetation. Science 278: 1411.

6. Mahlman JD (1997) Uncertainties in Projections of Human-Caused Climate Warming. Science 278: 1416-1417.

7. Guyon P, Graham B, Beck J, Boucher O, Gerasopoulos E, et al. (2003) Physical properties and Concentration of aerosol particles over the amazon tropical forest during background and biomass burning conditions. Atmospheric Chemistry and Physics 3: 951-967.

8. Buseck P R, Pósfai M (1999) Airborne minerals and related aerosol particles: effects on climate and the environment. Proc Natl Acad Sci Colloquium paper 96(7): 3372-3379.

9. Takaya H, Onda T, Harada M, Ogura N (1991) Distribution and sources of polycyclic aromatic hydrocarbons (PAHs) in street dust from Tokyo metropolitan area. Sci Total Environ 107: 45-69.

10. Sofilic T, Rastovcan Mioc A, Cerjan Stefanovic S, Novosel Radovic V, Jenko M (2004) Characterization of steel mill electric-arc furnace dust. Hazard Mater 109(1-3): 59-70.

11. Snider G, Weagle CL, Murdymootook, et al. (2016) Variation in globa chemical composition of PM2.5: emerging results from SPARTAN. Atmos Chem Phys 16: 9626-9653.

12. Chen W, Liu Y, Wang H, Hnizdo E (2012) Long-term exposure to silica dust and risk of total and cause-specific mortality in Chinese workers: a cohort study. PloS Med 9(4): 1-10 e1001206.

13. Jeong SH, Jeong HE, Byong KS (2011) Comparison of air pollution and the prevalence of allergy-related diseases in Incheon and Jeju City. Korean J Pediatrics 54(12): 501-506

14. Laney AS, Petsonk EL, Hale JM, Wolfe AL, Attfied MD (2012) Potential determinants of coal worker's pneumoconiosis, advanced pneumoconiosis, and progressive massive fibrosis among underground coal miners in the United States, 2005-2009. Am J Public Health 102 (Suppl 2): S279-283.

15. Moreno T, Kojima T, Querol X (2012) Natural versus anthropogenic inhalable aerosol chemistry of transboundary East Asian atmospheric outflows into western Japan. Sci Total Environ 424: 182-192.

16. Bharadwaj P, Burney J (2018) Cognition impact of sand and dust storms highlights future research needs? Lancet. Planet Health 2(5): e196-e197.

17. Kang D, Kim JE (2014) Fine, ultrafine, and yellow dust: emerging health problems in Korea. J Korean Med Sci 29(5): 621-622.
18. Wu JZ, Dan G, Lin fu Z, Ling Y, Ying Z, et al. (2018) Effects of particulate matter on allergic respiratory diseases. Chronic Dis Transl Med 4(2): 95102.

19. Chen B, Kan H (2018) Air pollution and population health: a global challenge. Environ Health Preventive Med 13(2): 94-101.

20. Reid JS, Hobbs PV (1998) Physical and optical properties of young smoke from individual biomass fires in Brazil. J Geo-phys Res atmos 103(24): 32013-32030

21. Andreae MQ (1991) Biomass burning: Its history, use, and distribution and its impacts on environmental quality and global climate, in Global biomass burning: atmospheric, climatic, and biospheric implications. JS Levine (Eds.), MIT Press, Cambridge, Mass, p. 3-21.

22. Kraeim N, Jeguirim M, Limousy L, Lajili M, Dorge S, et al. (2014) Impregnation of olive mill wastewater on dry biomasses: Impact on chemical properties and combustion performances. Energy 78: 479489 .

23. Lajili M, Limousy L, Jeguirim M (2014) Physico-chemical properties and thermal degradation characteristics of agropellets from olive mill byproducts/sawdust blends. Fuel Process Thechnol 126: 215-221.

24. Limousy L, Jeguirim M, Dutourmié P, Kraeim N, Lajili M, et al. (2013) Gaseous products and particulate matter emissions of biomass residential boiler fired with spent coffee grounds pellets. Fuel 107: 323329.

25. Jeguirim M, Limousy L, Fossard E (2016) Characterization of coffee residues pellets and their performance in residential combustor. Int J Green Energy 13(6): 608-615.

26. Marjamaki M, Keskinen J, Chen D, Pui D (2000) Performance evaluation of the electrical low pressure Impactor (ELPI). J Aerosol Sci 31: 249-261.

27. Jolliffe IT (2002) Principal Component Analysis. $2^{\text {nd }} e d \mathrm{p} \mathrm{cm}$ - (Springer series in statistics), 2002, 1986 Springer verlag New Yorc, Inc, USA.

28. Cardozo E, Erlich C, Alejo L, Fransson TH (2014) Combustion of agricultural residues: an experimental study for small-scale applications. Feul 115: 778-787.

29. Gonzalez JF, Gonzalez Garcia C, Ramiro A, Gonzalez J, Sabio E, et al. (2004) Combustion optimization of biomass residue pellets for domestic heating with mural boiler. Biomass Bioenergy 27: 145-154.

30. Rabaçal M, Femandes U, Costa M (2013) Combustion and emission characteristics of a domestic boiler fired with pellets of pine, industrial wood wastes and peach stones. Renew Energy 51: 220-226.

31. Verma VK, Bram S, Gauthier G, De Ruyck J (2011) Evaluation of the performance of a multi-fuel domestic boiler with respect to the existing European standard and quality labels: part-1. Biomass Bioenergy 35(1): 80-89.

32. Lajili M, Jeguirim M, Kraiem N, Limousy L (2015) Performance of a household boiler fed with agropellets blended from olive mill solid waste and pine sawdust. Fuel 153: 431-436.

33. Garcia Maraver A, Zamorano M, Femandes U, Rabaçal M, Costa M (2014) Relationship between fuel quality and gaseous and particulate matter emissions in a domestic pellet-fired boiler. Fuel 119: 141-152.

34. Zeng T, Weller N, Pollex A, Lenz V (2016) Blended biomass pellets as fuel for small scale combustion appliances: influence on gaseous and total particulate matter emissions and applicability of fuel indices. Fuel 184: 689-700.

35. Sommersacher P, Brunner T, Obemberger I (2012) Fuel indexes: a novel method for evaluation of relevant combustion properties of new biomass fuels. Energy Fuel 26(1): 380-390.

36. Elmay Y, Jeguirim M, Said R (2013) Energy recovery of date palm residues in a domestic pellet boiler. Fuel Process Technol 112: 12-18.

37. Johansson LS, Tullin C, Leckner B, Sjövall P (2003) Particle emissons from biomass combustion in small combustors. Biomass Bioenergy 25(4): 435-446. 
38. Jeguirim M, Kraeim N, Lajili M (2017) The relationship between mineral contents, particulate matter and bottom ash distribution during pellet combustion : molar balance and chemometric analysis. Environ Sci Pollut Res 24(11): 9927-9939.

39. Mueller Anneling LJ, O’Neil ME, Thorne PS (2006) Biomonitoring for assessment of organic dust-induced lung inflammation. Eur Resp J 27(6): 1096-1102.

40. Wagner GR (1997) Asbestosis and silicosis. Lancet 349: 1311-1315

ISSN: 2574-1241

DOI: 10.26717/BJSTR.2019.17.002979

Marzouk Lajili. Biomed J Sci \& Tech Res

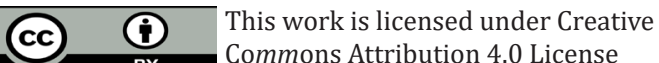

Submission Link: https://biomedres.us/submit-manuscript.php
41. Block ML, Calderón Garcidueňas (2009) Air pollution: mechanisms of neuroinflammation and CNS disease. Trends in Neurosci 32(9): 506516.

42. Kolpakova AF, Sharipov RN, Kolpakova FA (2017) Air pollution by particulate matter as the risk factor for the cardiovascular diseases. Gigiena I Sanitariia 96(2): 133-137.

43. Pinault LL, Weichental S, Crouse DL (2017) Associations between fine particulate matter and mortality in the 2001 Canadian Census Health and Environment Cohort. Environ Res 159: 406-415.

$\begin{array}{ll}\text { BIOMEDICAL } & \text { Assets of Publishing with us } \\ \text { RESEARCHES } & \text { - Global archiving of articles } \\ & - \text { Immediate, unrestricted online access } \\ & - \text { Rigorous Peer Review Process } \\ & \end{array}$

